\title{
Biopolymer flax (Linum Usitatissimum L.) and its prospects in biodegradable composite fabrication- a short review
}

\begin{abstract}
Linum Usitatissimum L. is mostly known as flax usually cultivated to consume the fibre demand for apparel and edible oil production. However, recent development and research work have made the diversification of flax polymers to be a part of a growing trend to fabricate biodegradable composites. Although, flax is traditionally grown for its natural plant oil seeds, but it also carries the prospects to be applied in bio-composites either in form of reinforcements or as polymer matrix. Since flax is a biodegradable polymer, the use of flax in composite reinforcement can introduce the concept of green composite that may contribute in lowering the carbon footprint around the globe. The inherent composite characteristics of flax fiber provide outstanding mechanical properties. Further, the technology for producing bio-based resin from flax oil for industrial application has added additional value offering significant opportunities for new and improved materials from renewable resources. This review intends to discuss few of the key points that summarize the promising features of flax in fabricating biodegradable composites. VARTM is one of the significant manufacturing methods of flax reinforced composites using non-woven flax mat where flax mat is usually formed by web formation method through air or wet lying technique. Flax fibre properties, effect of manufacturing parameters like needle punch density, mat areal density and consolidation pressure while manufacturing composites play an important role on the strength and modulus of flax reinforced composites.
\end{abstract}

Volume 5 Issue 5 - 2019

\author{
Md Shadhin, Ikra Iftekhar Shuvo \\ Department of Biosystems (Textiles) Engineering, University of \\ Manitoba, Canada
}

\begin{abstract}
Correspondence: Ikra Iftekhar Shuvo, Graduate Research Assistant, Department of Biosystems (Textiles) Engineering, University of Manitoba, Canada, Tel (43I) 373-3929. Email iishuvo123@gmail.com
\end{abstract}

Received: September 20, 2019 | Published: October 31, 2019

Keywords: flax, composite, resin, biopolymer, fibre

Abbreviations: PLA, polylactic acid; GSM, gram per square; MFA, metermicrofibril angle; PE, polyethylene; PS, polystyrene; $\mathrm{PP}$, polypropylene; RTM, resin transfer moulding; VARTM, vacuum assisted resin transfer molding; EFO, epoxidized flax oil; AEFO, acrylated epoxidized flax oil

\section{Introduction}

The polymers derived from the biological sources are usually known as the biopolymers, the history of which is reasonably older than the synthetic polymers. Biopolymers are considered to be one of the significant polymeric materials over the years for their performance in energy storage and preservation, transmission of genetic information, and cellular construction. The application of biopolymers has been diversified widely in recent days including biomedical and healthcare, bio-composites, and oil industries. Biopolymers are sustainable and environmentally friendly as they are biodegradable, made up of biological materials, and can reduce the carbon footprint on earth.

Flax (Linum Usitatissimum L.), one of the popular cellulose based biopolymers is best known as a plant from the Linum genus in the Linaceae family cultivated in cooler regions of the world for industrial purposes. The stems of flax plant grow about $80-120 \mathrm{~cm}$ in height. As a fast-growing plant, flax can reach its maturity in 100 days. Relatively low amount of fertilizer or pesticides is needed for flax cultivation compared to cotton.

It is widely used as a source of fibers in manufacturing textile products, which includes tops, bed sheets, underclothes, and table linen. However, it is used as a source of oil as well as (the basal component) an additive for various paints or polymers. Furthermore, the interest for flax fibers as a component of composites is growing in recent days. Composite materials consist of a matrix system reinforced with fibers. Mechanical analysis of the composites produced from flax fibers exhibit improved stiffness properties. ${ }^{2}$ Apart from the use of flax polymers as reinforcement in composites, one of the other significant end-use is the extraction of oil from flax seed which can be used for food and nutrition, paint binder, putty, and wood finish. However, in recent days efforts are given to develop biodegradable composite using flax as a resin (or matrix) manufactured from the biopolymer derived from the flax oil.

Recently, transgenic flax fibers are used for biomedical application. The application of transgenic flax fibers as medical devices is favorable because they are more biocompatible to the human body than those from a single material (other polymers, metals, or ceramics) as the composites produced from polylactic acid (PLA) matrix and transgenic flax reinforcement seem to have bacteriostatic, platelet anti-aggregated, and non-cytotoxic effect. Single-material devices are often too flexible or too weak or too stiff to host tissues, and some others such as nickel and chromium may also be sensitive to corrosion or cause allergic reactions. ${ }^{2}$ So, present research works in this sector are focused on developing biocompatible and bioactive composites reinforced with flax fibers derived from transgenic flax polymer. The interest for flax fibers and polymers is growing day by day both in plant science and engineering community as the later one utilizes the structural characteristics of flax within a frame work of composite materials whereas the previous one considers the flax plant as an important model for genomic studies. 


\section{Background}

The brief introduction of bio-based polymer, their major sources along with the classification is discussed here. The chemical components and morphology of flax fiber is discussed followed by their structural arrangement of crystalline and amorphous region as a representative of plant-based biopolymer. The mechanical properties of flax polymers and the factors affecting these properties are explained further. The application of flax polymer is elaborated in making polymer matrix composites using flax fiber as a reinforcement material and manufacturing resin from flax oil.

A polymer can be a three-dimensional network or two-dimensional network or a one-dimensional network made up of a long chain formed by repeating units linked together by covalent bonding where each repeating unit is the "-mer" or basic unit with "poly-mer" meaning many repeating units and are often made of carbon, hydrogen and sometimes oxygen, nitrogen, sulfur, chlorine, fluorine, phosphorous, and silicon. The chemical process of combining monomers together to form a single polymer is called polymerisation. In other words, the process of manufacturing polymers from their constituent monomers is called polymerisation. Produced polymers can be thermoplastic or thermosetting. In case of thermosetting polymer, linear polymers can be joined chemically by other chains at points along their length to make a crosslinked structure. The cross-linking agents are usually activated by heating, after which the material does not soften and melts when heated further. ${ }^{3}$ Thermosets are quite unique unlike the thermoplastics that melts and (destroys its physical integrity) when exposed to excessive heat beyond its tolerance limit. Unlike thermoplastics, thermosets resonate with their name and becomes permanently set to a physical structure after an initial heat treatment (or curing) during the design and production mechanics and no longer affected from excessive heat exposure.

Flax is a cellulosic bast fiber having cellulose as a major component, where cellulose (a semi-crystalline polysaccharide) provides the mechanical characteristics to the composite and hydrophilic properties to the fiber matrix interphase.

When two or more materials having different physical, chemical, mechanical properties are combined to manufacture a material of completely different characteristics from the individual components, the new material is called as a composite material. The main constituent of polymer matrix composites is matrix, reinforcement, and interphase. The use of natural fiber like flax polymer as a reinforced material is introduced here. Key factors like aspect ratio of fiber (1/d) and fiber volume fraction influence the composite properties.

\section{Objectives}

Non-woven mat that meets both manufacturing and functional requirement can be used to manufacture flax bio-composites. Previous studies focused on the optimization of glass fiber mats only for weight (GSM-Gram per Square Meter) to yield desired permeability and easy impregnation, compaction, final part thickness, and fiber volume fraction, and fibre - matrix interfacial bonding leaving a knowledge lack in the variability of flax fibre properties and optimisation of flax matt design and properties for composites fabrication. Hence, the main objectives of this study are to analyse fibre properties, understanding manufacturing methods and techniques of flax mat and flax reinforced composites, and study the effect of manufacturing parameters like needle punch density, consolidation pressure on the mechanical properties of flax reinforced composites.

\section{Biopolymers}

Biopolymers are made up of repeating chemical blocks to form chain-like molecules likewise in traditional polymers and can be very long in length. Living organisms or biological materials are the primary sources or raw materials of biopolymers. These natural raw materials are abundant, renewable, and biodegradable, making them attractive feed stocks for bio plastics, a new generation of environmentally friendly plastics.

\section{Sources of biopolymer}

There are two major sources of biopolymers. Living organisms are one of the sources of biopolymers, which include carbohydrates and proteins and the another is renewable resources, which need to be polymerized (e.g. lactic acid and triglycerides). Both types are used in the production of bio-plastics but the later one is the interesting development of biodegradable plastics from edible and non-edible vegetable oils, such as soybean oil, peanut oil, walnut oil, sesame oil, sunflower oil, and castor oil. ${ }^{4}$ In general, the major sources for different types of natural or biopolymers, are polysaccharides (e.g. starch, cellulose, and chitin) and proteins (e.g. collagen or gelatin, casein, albumin, fibrogen, silk). Other sources include lignin, lipids, shellac, and natural rubber. ${ }^{4}$

\section{Classification of biopolymer}

At present four types of biopolymers are available in market that can be categorized in four categories (sugar-based, starch-based, cellulose-based, biopolymer based on synthetic materials) as stated below ${ }^{5}$ :

\section{Sugar-based biopolymers}

Starch or Sucrose is used as input and lactic acid polymers (or polyactides) are manufactured in case of sugar-based polymers. Blowing, injection, vacuum forming, and extrusion are the most common methods of manufacturing sugar-based polymers. ${ }^{5}$

\section{Starch-based biopolymers}

Starch based biopolymers usually found in vegetables and can be obtained from wheat, tapioca, maize and potatoes. The materials of starch-based biopolymers are stored in tissues of plants as one way carbohydrates which usually composed of glucose. ${ }^{5}$

\section{Cellulose-based biopolymers}

Cellulose based Biopolymers are manufactured from natural resources like cotton, wood, wheat and corn. Cellular walls of plant are the primary constituent of cellulose-based biopolymers. ${ }^{5}$

\section{Biopolymer based on synthetic materials}

Biodegradable polymers can also be manufactured from synthetic compounds (obtained from petroleum) such as aliphatic aromatic co-polyesters. However, these polymers are completely compostable and bio-degradable although they are manufactured from synthetic compounds. ${ }^{5}$

\section{Flax- a cellulose-based biopolymer}

Flax is a cellulosic fiber and the fiber cells consist of thick secondary cell walls. ${ }^{6}$ These cells are several millimeters long and $15-25 \mathrm{~mm}$ in diameter. Cellulose, hemicelluloses - xylan, lignin, and pectins are three polysaccharides groups that form the main biopolymers of 
the flax bast fibers. ${ }^{1}$ Flax fiber contains $60-80 \%$ cellulose and the remaining material is rich in water-soluble polysaccharides, proteins and phenolics. ${ }^{6}$ The non-cellulosic part is amorphous whereas the cellulosic part is crystalline and responsible for maximum properties and provides strength to materials.

\section{Structure of flax}

The technical fiber of flax consists of elementary fibers (single plant cells, e.g. cellulose) glued together by a pectin interface. The length of elementary fiber ranges between $2-5 \mathrm{~cm}$ and diameters between $10-25$ $\mu \mathrm{m}$ as shown in Figure 1. They are not circular but a polyhedron with 5 to 7 sides to improve the packing in the technical fiber. ${ }^{7}$

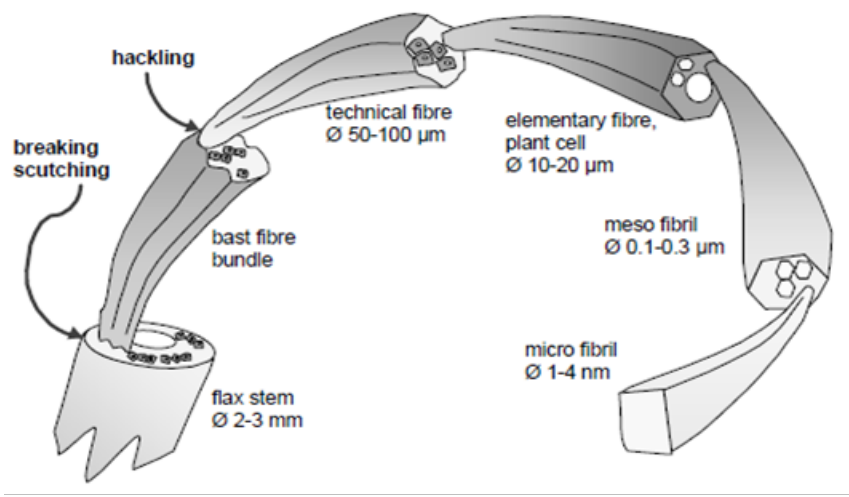

Figure I Schematic diagram displaying the structure flax fiber. ${ }^{7}$

The structure of flax is made up with cuticle connected with a single layer epidermis, fibers in cortical region, and a woody core tissues arranged from outer to inner layers as illustrated in Figure 2 observed under polarized light microscopy. ${ }^{8}$ Cuticle resides at the outermost part of the stem (Figure 2). Lipids, including waxes and cutin, and aromatics comprise this layer and provide a protective barrier to water loss and to invading microbial pathogens into the internal stem tissues. Flax contains no or a small amount of wax on fibers can be assessed through the no staining of flax with oil-red illustrated in Figure $3 .^{8}$ Inner Core Cells or the central woody core tissues are the primary xylem and other structural cells, which provide support and water conduction for the plant. The core cells are about $65 \%-75 \%$ of stem material.

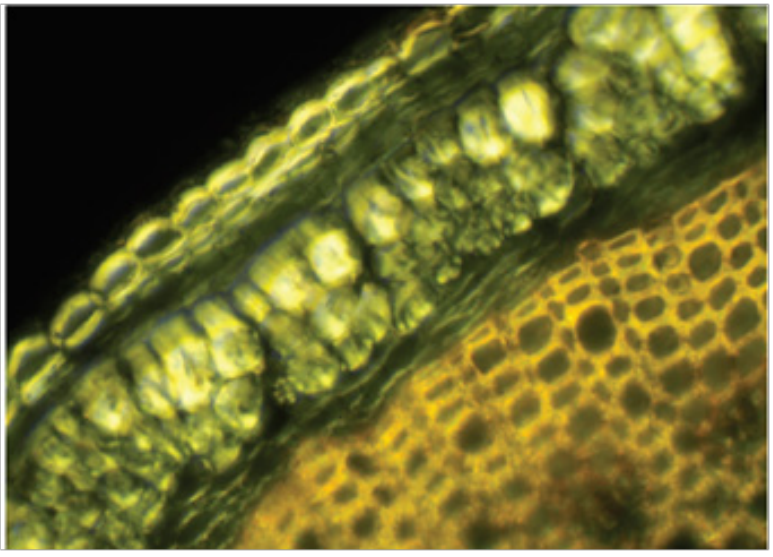

Figure 2 Free-hand cross-section of flax stem observed by polarized light microscopy showing the outermost cuticle/epidermal layer, birefringent fibers in bundles, and innermost core tissues. ${ }^{8}$

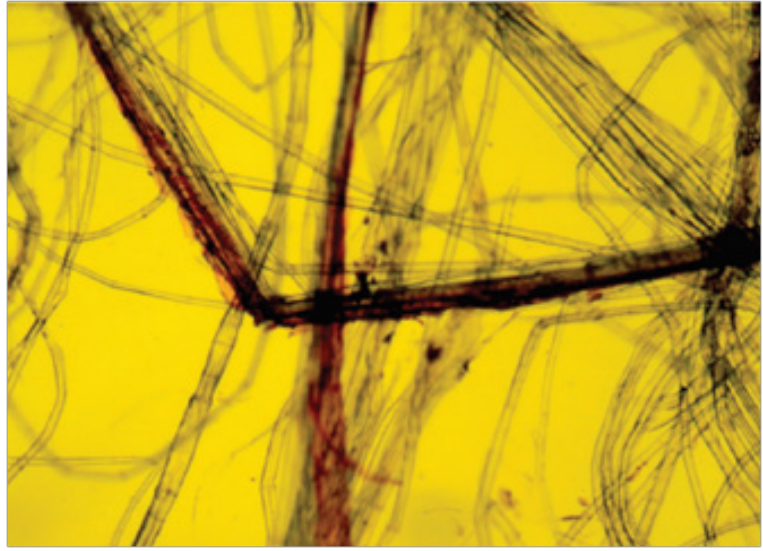

Figure 3 Light micrograph of processed fibers stained with oil-red showing cuticle remnants still attached to the fibers. ${ }^{8}$

\section{Morphology of flax}

Flax fibers are extracted from the phloem tissue consisting of elongated cells with a thick secondary cell wall that encircles the vascular bundle (pith and xylem) of the flax stem. Elongated crystallites of cellulose are assembled longitudinally forming longer nanofibers. These nanometric fibers are coated with hemicelluloses and pectins and enable the crystallites to agglomerate laterally to form the microfibrils that are in a range of $40-200 \AA$ width. ${ }^{1}$ These microfibrils are assembled in a twisted helical manner within various layers. The primary cell wall comprises of a thin external layer and the secondary cell wall is the main part of the cell wall made up of three sub-layers $\left(\mathrm{S}_{1}, \mathrm{~S}_{2}\right.$, and $\left.\mathrm{S}_{3}\right)$ that are arranged concentrically. The average twist angle or the microfibril angle ranges between $3.5-10^{\circ}$. There can be significant variations in the microfibril angle (MFA) between the various sub-layers, but its low value means an overall high degree of order along the fiber direction. This sophisticated supramolecular organization explains the superior longitudinal mechanical properties of the fibers. The high molecular weight of cellulose chains of flax fiber contributes significantly for its outstanding mechanical properties. ${ }^{1}$ In some recent studies, the morphology of the flax phloem fibers are re-considered under a different light. ${ }^{9}$ Flax fibers display a quasi-absence of lignin, a high cellulose content, and a high pectin content when compared to other sclerenchyma fibers exhibiting the characteristics of gelatinous layer or G-layer. ${ }^{9}$ These gelatinous layers are usually found in hardwood which generates compression wood which is characterized by a relatively high microfibril angle and a highly lignified cell wall.'

\section{Chemical composition of flax}

The chemical composition of flax fibers is listed in Table 1 stated in different studies which defines the properties of flax fiber. ${ }^{10}$ As described earlier flax is rich in cellulose accounts for around $70 \%$ of total composition determining the physical properties of the fibers and hemicellulose, wax, lignin and pectin is also present in varying quantities. Cellulose is a polysaccharide which contains a large amount of hydroxyl group provides hydrophilic nature to natural fiber when used to reinforce hydrophobic matrices and hemicelluloses are bound to cellulose fibrils presumably by hydrogen bonds having a branched, amorphous and significantly lower molecular weight structure. The waxy substances of flax fibers affect the fiber wettability and adhesion 
characteristics..$^{10}$ Lignins are amorphous, highly complex, mainly aromatic, polymers of phenylpropane units but have the least water sorption of the natural fiber components. ${ }^{11}$

Table I Chemical composition of flax fiber ${ }^{10}$

\begin{tabular}{llllll}
\hline $\begin{array}{l}\text { Cellulose } \\
\%\end{array}$ & $\begin{array}{l}\text { Hemi- } \\
\text { cellulose } \%\end{array}$ & $\begin{array}{l}\text { Pectin } \\
\%\end{array}$ & $\begin{array}{l}\text { Lignin } \\
\%\end{array}$ & $\begin{array}{l}\text { Wax } \\
\%\end{array}$ & $\begin{array}{l}\text { M.Ca } \\
\%\end{array}$ \\
\hline 64.1 & 16.7 & 1.8 & 2 & 1.5 & 10 \\
$71-75$ & $18.6-20.6$ & 2.2 & 2.2 & 1.7 & 10 \\
\hline
\end{tabular}

\section{Crystalline and amorphous structure of cellulose}

Considering cellulose as a major component of flax polymer, the crystalline and amorphous structure of cellulose has been discussed here through analysis of molecular modelling. ${ }^{12}$ Molecular modeling has been performed on three cellulosic systems to emphasize how crystalline and amorphous celluloses differ and to analyse the individual cellulose chains conformational behavior, interchain reaction, and glass transition temperature. The three cellulosic systems include two native crystalline phases (I $\alpha$ and $\mathrm{I} \beta$ ) and an amorphous phase, constituted by four independent microstructures. ${ }^{12}$

The main structural contribution of cellulose comes from CP/MAS $13 \mathrm{C}$ NMR, which proves the existence of two allomorphs, named I $\alpha$ and $\mathrm{I} \beta$ in the crystal phases of native cellulose samples..$^{13}$ Molecular modeling has been used to ease the complication of the quantitative analysis of X-ray diffraction to determine the best and consistent coordinate set within the unit cells for both diffraction data and total potential energy. ${ }^{14}$ The modelled microstructure of two native I $\alpha$ and $\mathrm{I} \beta$ crystallographic phases and an amorphous solid has been illustrated in Figure 4. ${ }^{12}$ The fibrils of crystalline cellulose are oriented at an angle of about $\pm 10^{\circ}$ with the fiber axis in the cell wall and provide high tensile strength to fiber. ${ }^{7}$ A helix forms the individual chains having two residues per turn and a pitch of $10.34 \AA$ which are aligned parallelly to the fiber axis direction. The two chains of the monoclinic phase are not symmetric in nature as the central chain is slightly rotated with respect to the corner chain. The cohesion of chains depends on hydrogen bonds disclosed through vibration spectroscopy. ${ }^{15}$
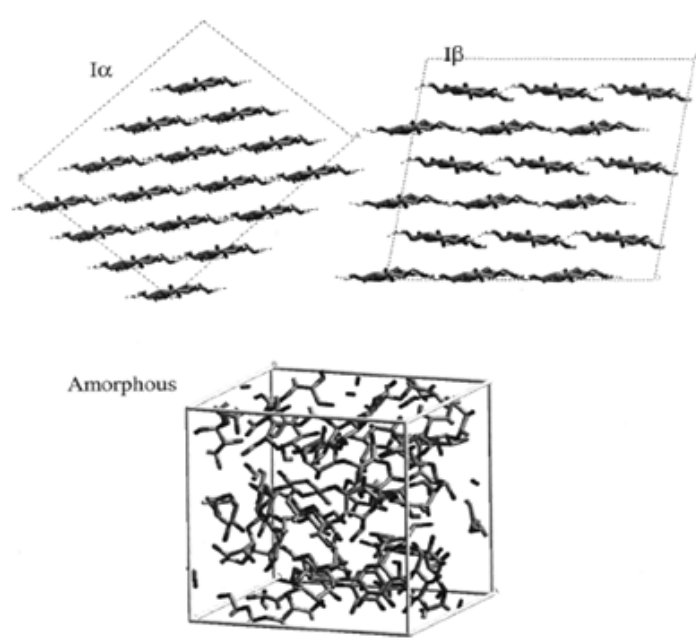

Figure 4 Modelled microstructures of $I \alpha, I \beta$, and amorphous solid. ${ }^{2}$
However, structural information on amorphous cellulose is limited compared to crystal structures of cellulose and molecular modeling is a well adapted technique in such case to study the arrangement of the cellulose chains within the material. ${ }^{12}$ The absence of long-range order in amorphous cellulose was examined by wide-angle X-ray scattering-WAXS ${ }^{16}$ and small angle X-ray scattering-SAXS. ${ }^{17}$ Both the crystalline and amorphous microstructures were studied, analysed, and summarised as below.

\section{Crystalline microstructures of cellulose}

Previous study described the chain conformations and cell dimensions of cellulose. ${ }^{18}$ The building block of cellulose is illustrated in Figure 5. The computational box of cellulose consists of $(3 \times 3 \times 2)$ unit cells. Coordinates of cellulose are positioned in a crystalline supercell subjected to periodic boundary conditions in all three directions. The edge dimensions of the supercell are exactly the sum of all the elementary cells that were used. The models of the I $\alpha$ and I $\beta$ consist of 16 and 18 chains, respectively having a degree of polymerization of 4 for each chain. The computational system consists of 32 cellobiose units for $\mathrm{I} \alpha$ and 36 for $\mathrm{I} \beta$. However, the glucose residues are linked with covalent bond to model the infinite chain length. ${ }^{12}$

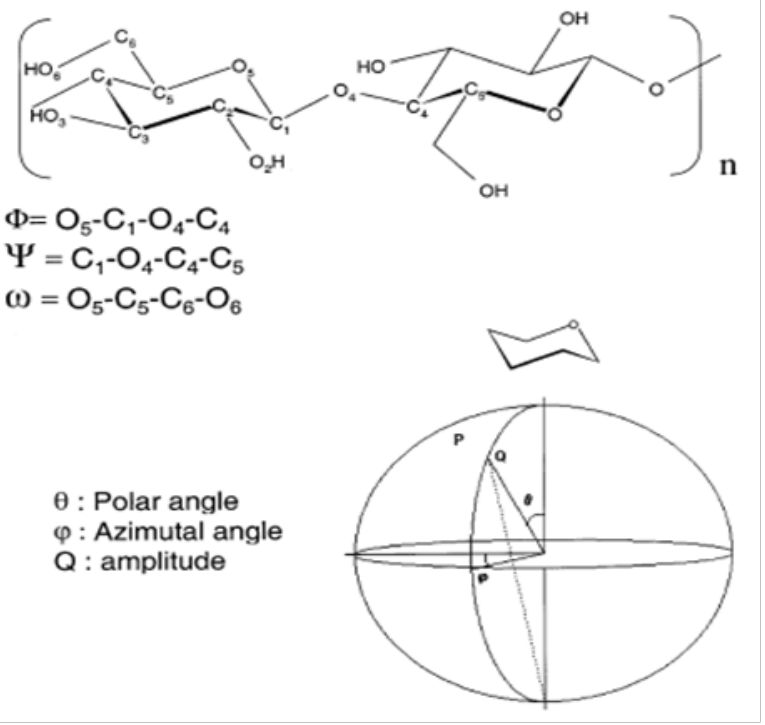

Figure 5 Conformational parameters of cellulose. ${ }^{12}$

\section{Amorphous microstructures of cellulose}

A polymer in a condensed amorphous state exists in a nonperturbed conformation stated by Flory in conformational investigation of polymers. ${ }^{19}$ The theory is based on a hypothesis that the torsion angles of each glycosidic bond experience values characteristic of those computed for the isolated dimeric fragment. The geometry of the final equilibrated system is close to that of the initial system, often time observed for the modeling of the amorphous solids and a very few minor changes in conformational during the whole equilibration process. It is therefore important to reproduce the conformational preferences of cellulose at the generation step. ${ }^{12}$

\section{Mechanical properties of flax polymer}

The structure of flax fiber behaves like a composite material. ${ }^{6}$ Higher axial stiffness and strength of flax fiber reflects their composite internal structure consisting of highly crystalline and oriented cellulose 
microfibrils. ${ }^{7}$ The mechanical properties of flax can be explained using the theory of composite materials. ${ }^{7}$ Secondary cell-wall of flax is a composite of strong cellulose microfibrils embedded in a weaker matrix of other polymers. More surface area will be available for longer and thinner fibers to transmit the stresses from the matrix to fiber. Again, longer and thinner fiber will result in higher aspect ratio. Flax fiber has a high aspect ratio (1/d) of around 100 and the it is still higher for cellulose microfibrils within their secondary walls which allow the elementary fibers to approach the theoretical tensile strength of cellulose in the same range of advanced synthetic fibers like carbon and Kevlar.

However, in recent days flax fibers are considered to be as a best potential to replace glass in polymer matrix composites due to their promising specific properties. A comparison of mechanical properties of flax and E-glass are listed in Table 2.

Table 2 Mechanical properties of flax and E-glass fiber ${ }^{7}$

\begin{tabular}{llllll}
\hline Fibers & $\begin{array}{l}\text { Modulus } \\
(\mathrm{GPa})\end{array}$ & $\begin{array}{l}\text { Strength } \\
(\mathrm{MPa})\end{array}$ & $\begin{array}{l}\text { Density } \\
\left(\mathrm{g} / \mathrm{cm}^{3}\right)\end{array}$ & $\begin{array}{l}\text { Specific } \\
\text { modulus }\end{array}$ & $\begin{array}{l}\text { Specific } \\
\text { strength }\end{array}$ \\
\hline E-glass & 72 & 3530 & 2.54 & 28.2 & 1390 \\
& & & & & \\
Flax & $50-70$ & $500-900$ & $1.4-1.5$ & 41 & 480 \\
\end{tabular}

\section{Methodology}

\section{Materials}

Flax fibres were used as raw material to manufacture non-woven matt which works as reinforcement in thermoset polymer matrix resin system. Curing is one of the significant steps while manufacturing polymer matrix composites and a curing initiator is required for this along with matrix resin system. A vacuum pump, mold release agent, and vacuum bagging material are needed to be used for resin impregnation of non-woven flax matt.

\section{Flax biopolymers in polymer matrix composites}

Polymer matrix holds the fibers together to provide a shape in natural fiber polymer based composites and responsible for the load transfer to the fibers by adhesion and/or friction. ${ }^{10}$ The adhesive or resin is used as a matrix to the composite structure which helps to prevent premature failure due to fiber micro-buckling. Matrix also provides rigidity and shape to structural member, influence the performance behaviours such as impact and ductility. ${ }^{10}$ Polyesters, epoxies, bismaleimides, and cyanate esters, polyimides, and phenolics are the most commercially used adhesives for matrix resin system. ${ }^{20}$ The commonly used thermoplastic polymer matrix is polypropylene (PP) and several synthetic thermoplastics such as polyethylene (PE), polystyrene (PS) and the primary thermoset resins used are polyester, vinyl ester, and epoxy resins. Epoxy resins offer high mechanical performance (with respect to tensile strength and modulus, and compressive strength) and solvent resistance to environmental degradation. ${ }^{10}$ The mechanical properties of epoxy resins are mentioned in Table $3 .^{21}$
Table 3 Mechanical properties of epoxy resin ${ }^{21}$

\begin{tabular}{ll}
\hline Properties & Value \\
\hline Tensile Strength (MPa) & $55-130$ \\
Tensile Modulus (GPa) & $2.7-4 . \mathrm{I}$ \\
Flexural strength (MPa) & $\mathrm{I}$ I0-150 \\
Flexural modulus (GPa) & $3-4$ \\
Cure shrinkage (\%) & $\mathrm{I}-5$ \\
\hline
\end{tabular}

\section{Manufacturing of non-woven flax matt}

Flax fibers are used as reinforcement in polymer matrix composite in the form of chopped fibers, mats, rovings, yarns, and fabrics as illustrated in Figure 6. Nonwoven mats are being used widely for industrial application because of their higher permeability and better friction compared to woven products. ${ }^{22}$ Bio-based and biodegradable nonwoven geotextiles can be made from hemp, flax, jute, kenaf and bagasse. ${ }^{23}$ Web formation and binding are the two major steps in mat manufacturing. Web formation can be done through three methods. These are
a) Air laying
b) Wet laying
c) Spun laying. ${ }^{22}$
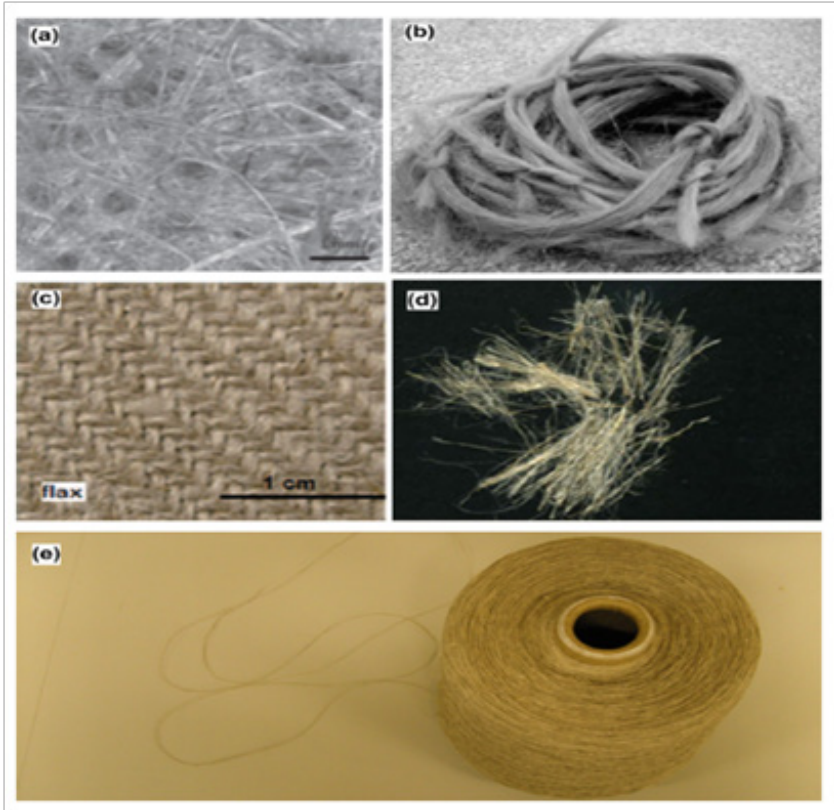

Figure 6 Different configuration of flax biopolymers, such as mat (a), roving (b), fabric (c), monofilament fiber (d), and flax yarn (e) available for applications as reinforcements to form composites. ${ }^{10}$

Spun lying is mostly used for synthetic filaments. In air laying, fibers are usually separated by a mechanical comb, suspended in air, and dropped on to a moving conveyor belt to form the web of fibers. In wet laying, fibers are suspended in water are collected on a screen, drained of any entrapped water, and dried to form the web. 


\section{Manufacturing of flax reinforced polymer matrix composites}

Various manufacturing techniques have been developed over time to produce composites that include film stacking, vacuum infusion, hand lay-up, compression moulding, resin transfer moulding (RTM), injection moulding, and pultrusion. ${ }^{10}$ Desired manufacturing technique is selected based on the end-use of the composite material, size and shape of the composites, and manufacturing cost. The combination of hot-press and autoclave process is known as compression moulding technique. Hand lay-up is a widely used in civil infrastructure to retrofit and strengthen structure with carbon or glass fiber reinforced composites. Liquid composite moulding technique includes RTM, vacuum infusion, structural reaction injection moulding, and other subsets. The principle of liquid composite molding is to separately inject and liquid resin into a bed of stationary preforms. ${ }^{24}$

O'Donell et al..$^{25}$ used VARTM (vacuum assisted resin transfer molding) to manufacture flax composites with canola oil-based resin. Two types of adhesive bonded flax mats were used. The adhesive used for bonding was polyethylene (PET). The weight fraction of fibers to adhesive was altered and it was 60/40 and 85/15. Van den Oever et al. ${ }^{22}$ studied the mechanical properties of wet-laid flax mat composites. Mieck et al. ${ }^{23}$ studied the properties of needle punched flax mat impregnated with polypropylene. Williams et al. ${ }^{26}$ manufactured new composites using fibres and resin from renewable sources. They used natural fiber composite with soybean based thermoset resin by the RTM (Resin Transfer Molding) process. Random flax and pulp cellulose mat composites were manufactured where the mats were bonded by $5 \%$ (weight fraction) of a starch adhesive, before composite manufacturing. The effect of needle punching, fiber treatment and press temperature was studied on needle punched flax/polypropylene composite Van De Velde et al..$^{27}$ having a $60 \%$ weight fraction of flax fibers in composites. Flax composites were manufactured using nonwoven flax mat and polyester resin was studied $i^{28}$ and the effect of needle punch density and consolidation pressure was studied on it.

VARTM (Vacuum Assisted Resin Transfer Molding) is one of the composites manufacturing processes with natural fibre that uses only vacuum pressure for both injection and cure. Schematic diagram of a typical VARTM process is illustrated in Figure 7 that consists of a single-sided tooling with a vacuum bag with porous medium on top of the preform to facilitate resin flow. The porous medium should include a highly permeable material that will allow resin to flow easily through the material. ${ }^{29}$

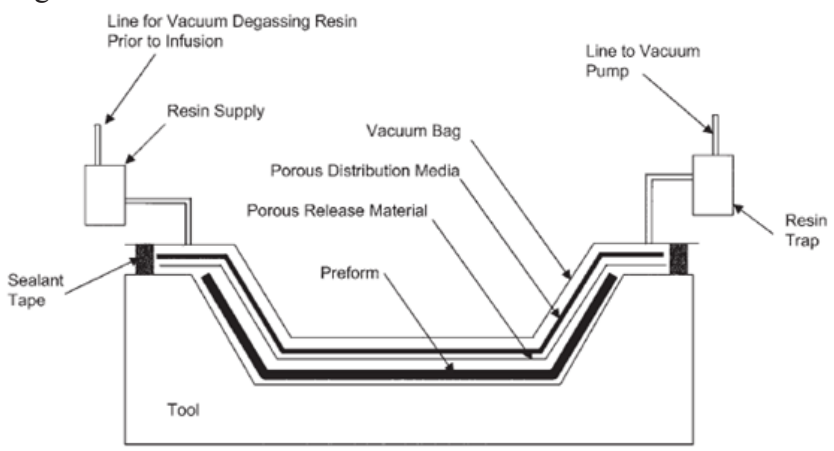

Figure 7 Schematic diagram of a typical VARTM (vacuum assisted resin transfer molding) process setup. ${ }^{29}$

\section{Application of flax in manufacturing oil-based biopolymer (resin)}

Flax is manufactured for its natural oil rich plant seed. The manufacturing process of biopolymer resin derived from flax oil was developed first time for to be used further in biodegradable composite. For the manufacturing of polymer resin polymer, triglyceride unsaturation structure of the flax oil was converted to epoxy oil and reacted with acrylic acid to form acrylated epoxidized flax oil and then it was blended with styrene and cured to form polymer resin. The chemical concentration and temperature of the reaction and time influenced the formation of epoxidized oil and acrylated epoxidized flax oil. . $^{30}$

\section{Synthesis of oil}

Flax oil was mixed with hydrogen peroxide $(30 \%)$ and formic acid (85\%) in a weight ratio of 50: $45: 17$ and stirred at $25^{\circ} \mathrm{C}$ for 17 hours for the synthesis of epoxidized flax oil (EFO). The epoxidized flax oil was then dissolved in ether and washed with saturated sodium bicarbonate solution for neutralization and dried over sodium sulfate. A separating funnel was used to separate the oil and water phase of the solution. Again, epoxidized flax oil was combined with acrylic acid in a weight ratio of $1: 3$ and stirred at $70^{\circ} \mathrm{C}$ for 4 hours for producing acrylated epoxidized flax oil (AEFO) and resin. The acrylated epoxidized flax oil was then mixed with styrene in a weight ratio of 100:45. The produced resin was subjected to curing at a temperature of $90^{\circ} \mathrm{C}$ for 1 hour and $110^{\circ} \mathrm{C}$ for 2 hours. ${ }^{30}$

\section{Factors affecting processing of bio-based resin}

The manufactured polymer resin exhibits rigid properties and an obvious crystallization temperature. The influence of mole fraction, concentration and temperature of reaction, curing time, and weight ratio of mixing are studied to understand how they affect processing parameters of resin manufacturing from flax oil. ${ }^{30}$ The mole fraction and concentration of hydrogen peroxide and formic acid to form epoxidized flax oil have to be kept in a certain ratio to open the double bond of triglyceride for future polymerization. The reaction temperature should be less than approximately $85^{\circ} \mathrm{C}$ to avoid foam generation. 1.5 hour and $120^{\circ} \mathrm{C}$ were found optimum curing that result in highest melting temperature and crystallization temperature.

\section{Discussion}

\section{Flax matt composites}

According to Van den Oever et al., ${ }^{24}$ flax mat composite had a tensile modulus of $5 \mathrm{GPa}$ having $20 \%$ volume fraction of fibers which indicated that the transverse properties of flax composites were considerably lower than its longitudinal properties. However, the effect of mat manufacturing parameters was not discussed here.

According to Van De Velde et al. ${ }^{27}$ the second time needle punching of the matt caused the areal density of needle punched mat decreased from $918 \mathrm{~g} / \mathrm{m}^{2}$ to $887 \mathrm{~g} / \mathrm{m}^{2}$. The properties of composite degraded for twice needle punched panels especially at higher press temperatures. However, the tensile modulus and the strength of the composite were degraded due to alkaline treatment of fibres.

According to Williams et al. ${ }^{26}$ the modulus of flax composites was around $2 \mathrm{GPa}$ having a $15 \%$ weight fraction of fibres where the mats were bonded by $5 \%$ (weight fraction) of a starch adhesive. 
According to Mieck et al..$^{25}$ the tensile modulus of composites was $8 \mathrm{GPa}$ and $6 \mathrm{GPa}$, in transverse and longitudinal directions respectively having a $30 \%$ weight fraction of fibres. The manufactured flax composite here shows an increase in tensile modulus with the increase in areal density due to an increase in volume fraction of fibres in composites.

According to Williams et al. ${ }^{26}$ the modulus of flax composites was found $2 \mathrm{GPa}$ that contains around $15 \%$ weight fraction of fibers. However, the details on punch density and depth were not discussed here.

\section{Effect of consolidation pressure}

Fahimian ${ }^{28}$ discussed the effect of consolidation pressure on hemp matt composites. According to Fahimian ${ }^{28}$ volume fraction of fibres increases in needle-punched hemp composites with applied pressure for a given punch density. However, the rate of increase differs with punch density of matt during composite manufacturing.

The rate of increase in applied pressure for a unit increase in thickness (i.e. fiber volume fraction), which is a measure of rate of stiffening of the mat, varied widely with punch density highlighting the impact of mat structure on the compaction behavior. A clear trend in the effect of punch density on the rate of stiffening could not be discerned due to variation in the areal density of the mat, which altered the mat structure and hence, the compaction behavior.

\section{Conclusion}

The use of flax fiber in polymer matrix composite as a reinforcement is increasing day by day and it stands as a strong and potential candidate for the replacement of existing thermoplastic, thermosetting polymers and other synthetic fibers. Different methods and technique of manufacturing non-woven flax mat using flax fibre, manufacturing methods of flax reinforced composites using nonwoven flax mat, and synthesis of bio-based resin matrix systems from flax have been reviewed in this study. However, the analysis of fibre properties, suitability of manufacturing methods, and effect of manufacturing parameters like needle punch density, areal density and consolidation pressure of flax reinforced composites have been also reviewed in this article. The strength and modulus of flax reinforced composites are greatly influenced by volume fraction of fibres. For a given punch density volume fraction of fibres can be increased in needle-punched flax composites with applied pressure. Most of the synthetic polymers are difficult to dispose as they can take many years to degrade. Hence, the prospect of flax in bio-composites should be studied further. Future work can be done on the progress of chemical modifications of the matrix and fiber surface and use of adhesion promoters to improve mechanical properties of flax fiber reinforced composites to understand the durability of the flax bio-composites.

\section{Acknowledgments}

The authors would like to extend their gratitude to University of Manitoba.

\section{Funding}

None.

\section{Conflicts of interest}

The authors declare that they have no competing interests.

\section{References}

1. Duchemin B, Thuault A, Vicente A, et al. Ultrastructure of cellulose crystallites in flax textile fibres. Cellulose. 2012;19(6):1837-1854.

2. Wróbel-Kwiatkowska M, Czemplik M, Kulma A, et al. New biocomposites based on bioplastic flax fibers and biodegradable polymers. Biotechnol Prog. 2012;28(5):1336-1346.

3. Rao NS. Mechanical properties of solid polymers. 2017.

4. Jacob John M, Thomas S. Natural polymers: an overview. 2012;1:1-7.

5. Chemistry Learner. 2019.

6. Girault R, Bert F, Rihouey C, et al. Galactans and cellulose in flax fibres: Putative contributions to the tensile strength. Int J Biol Macromol. 1997;21(1-2):179-188.

7. Charlet K, Jernot JP, Gomina M, et al. Mechanical properties of flax fibers and of the derived unidirectional composites. 2009;44(24):28872896.

8. Akin DE. Linen most useful: perspectives on structure, chemistry, and enzymes for retting flax. ISRN Biotechnol. 2012;2013:1-23.

9. Salnikov V V, Ageeva MV, Gorshkova TA, et al. Specific type of secondary cell wall formed by plant fibers. Russ $J$ Plant Physiol. 2010;57(3):328-341.

10. Yan L, Chouw N, Jayaraman K. Flax fibre and its composites - a review. Compos Part B Eng. 2014;56:296-317.

11. Fiore V, Valenza A, Di Bella G. Mechanical behavior of carbon/ flax hybrid composites for structural applications. J Compos Mater. 2012;46(17):2089-2096

12. Mazeau K, Heux L. Molecular dynamics simulations of bulk native crystalline and amorphous structures of cellulose. J Phys Chem B. 2003;107(10):2394-2403.

13. Rajaji H Atalla, David L VanderHart. Native cellulose: a composite of two distinct crystalline forms. American Association for the Advancement of Science Stable. 2011;223(4633):283-285.

14. Finkenstadt VL, Millane RP. Crystal structure of valonia cellulose I $\beta$. Macromolecules. 2002;31(22):7776-7783.

15. Barbara H, Lennart S. Application of dynamic 2D FTIR to cellulose. Vib Spectrosc. 2000;22(1-2):111-118.

16. Paul D, Philipp B, Fink H-P, et al. The structure of amorphous cellulose as revealed by wide-angle X-ray scattering. Polymer. 2003;28(8):12651270 .

17. Grigoriew H, Chmielewski AG. Capabilities of X-ray methods in studies of processes of permeation through dense membranes. J Memb Sci. 1998;142(1):87-95.

18. Vietor RJ, Mazeau K, Lakin M, et al. A priori crystal structure prediction of native celluloses. Biopolymers. 2000;54(5):342-354.

19. Paul J, Volkenstein FM. Statistical mechanics of chain molecules. Biopolymers. 1969;8(5):699-700.

20. Materials SC, Campbell FC. Matrix Resin Systems. Struct Compos Mater. 2010:63-100.

21. Kong $\mathrm{C}$, Lee H, Park H. Design and manufacturing of automobile hood using natural composite structure. Compos Part B Eng. 2016;91:18-26.

22. Van Den Oever MJA, Bos HL, Molenveld K. Flax fibre physical structure and its effect on composite properties: Impact strength and thermomechanical properties. Angew Makromol Chemie. 1999;272(1):71-76. 
23. Mieck KP, Lützkendorf R, Reussmann T. Needle-punched hybrid nonwovens of flax and PPFibers-Textile semiproducts for manufacturing of fiber composites. Polym Compos. 1996;17(6):873-878.

24. Ho MP, Wang $\mathrm{H}$, Lee JH, et al. Critical factors on manufacturing processes of natural fibre composites. Compos Part B Eng. 2012;43(8):3549-3562.

25. O’Donnell A, Dweib MA, Wool RP. Natural fiber composites with plant oil-based resin. Compos Sci Technol. 2004;64(9):1135-1145.

26. Williams GI, Wool RP. Composites from natural fibers and soy oil resins. Appl Compos Mater. 2000;7(5-6):421-432.
27. Velde K Van De, Kiekens P. Effect of flax/PP panel process parameters on resulting composite properties. 2003;16(5):413-431.

28. Fahimian M, Philosophy DOF. Processing- structure- property relationship in needle-punched nonwoven natural fiber mat composites. 2013.

29. Campbell FC. Thermoset composite fabrication. Struct Compos Mater. 2010:119-82.

30. Panigrahi S, Li X, Dhakal NH, et al. Development of flax oil-based biopolymer for biocomposites. SAE Int J Commer Veh. 2010;2(2):123130 . 